\title{
LA FILOSOFÍA DE LA NATURALEZA DE AUGUSTO GONZÁLEZ DE LINARES (1845-1904)
}

\author{
Carlos Nieto Blanco \\ Universidad de Cantabria \\ carlos.nieto@unican.es
}

Recibido: 19 noviembre 2012; Aceptado: 1 abril 2013.

Cómo citar este artículo/Citation: Nieto Blanco, Carlos (2013), "La filosofía de la Naturaleza de Augusto González de Linares (18451904)", Asclepio 65 (2): p025. doi: http://dx.doi.org/10.3989/asclepio.2013.25

RESUMEN: El naturalista Augusto González de Linares es conocido por haber sido el fundador del primer Laboratorio de Biología Marina en España, creado en 1886, y que se estableció en Santander en 1890, pero se interesó también por la Filosofía de la Naturaleza, desde la que orientó su actividad como científico. Participó en la recepción crítica de las ideas evolucionistas en la España de la Restauración, interesándose por la obra de Darwin y Haeckel. Criticó el «mecanicismo» de Darwin por atribuir al medio la causa principal del proceso evolutivo, despreciando el papel de la herencia, y rechazó también el materialismo de Haeckel. La Filosofía de la Naturaleza de Augusto González de Linares está influida por la Naturphilosophie alemana, con especial referencia a Schelling, Oken, Carus, y por Krause, e incluye dos aspectos. En Ontología, defiende la tesis de un monismo organicista, mientras que en Epistemología, sostiene que es necesario reorganizar todas las ciencias desde la unidad que representa la Filosofía, proponiendo una coordinación entre el hecho y la idea.

PALABRAS CLAVE: Herencia; idea; krausismo; monismo; vitalismo.

\section{THE PHILOSOPHY OF NATURE OF AUGUST GONZÁLEZ DE LINARES}

ABSTRACT: The naturalist Augusto González de Linares is known for being the founder of the first Marine Biological Laboratory in Spain, created in 1886, and which was established in Santander in 1890, but he was also interested in Philosophy of Nature, from which focused his activity as a scientific. He taked part in the critical reception of the evolutionist ideas in the Spain of the Restoration, interesting in the work of Darwin and Haeckel. He criticized the "Mecanicism" of Darwin, because he confered the environment as the main cause of the evolutionary process, rejecting the rol of heredity, and also refussed the Materialism of Haekel. The Philosophy of Nature of Augusto González de Linares was influenced by the German Naturphilosophie, with special reference to Schelling, Oken, Carus, and to Krause, and includes two aspects. In Ontology, defends the thesis of an organicist Monism, while in Epistemology, argues that it is necessary to reorganize all sciences from the unity that means the Philosophy, proposing a coordination betwen the fact and the idea.

KEY WORDS: Heredity; Idea; Krausism; Monism; Vitalism.

Copyright: ( 2013 CSIC. Este es un artículo de acceso abierto distribuido bajo los términos de la licencia Creative Commons Attribution-Non Commercial (by-nc) Spain 3.0. 


\section{INTRODUCCIÓN}

Las referencias historiográficas en las que aparece mencionado este naturalista suelen abundar en su papel de fundador de la primera Estación costera de Biología Marina española, creada en 1886, y radicada en Santander a partir de 1890, centrando en esta actividad su contribución profesional a la ciencia, pero apenas se adentran en su faceta de filósofo de la Naturaleza, a excepción de algunos trabajos recientes (Simó Ruescas, 2004; 2011). Habiendo dedicado algunos estudios monográficos al conjunto de su obra (Nieto Blanco, 2004; 2009; 2010; 2011), en los que he destacado sus aportaciones científicas referidas a la historia intelectual del periodo, y estando a punto de aparecer la edición de su Obra completa, de la que me ocupo como editor literario, la cual va precedida de un amplio estudio preliminar en el que sitúo in extenso la personalidad intelectual de nuestro autor en el contexto de la historia cultural -con especial referencia al pensamiento científico y filosófico- de su tiempo (Nieto Blanco, en González de Linares, en prensa), he creído oportuno no reiterar esas aportaciones, anticipando esta dimensión menos conocida de su pensamiento, especialmente por ser la filosofía de un científico experimental y no la de un filósofo profesional.

\section{RECEPCIÓN CRÍTICA DEL EVOLUCIONISMO: DARWIN Y HAECKEL}

Aunque Augusto González de Linares alcanzase una cierta notoriedad en su etapa de profesor en la universidad compostelana (1872-1875) por propagar, tanto en el aula como en foros escolares, las nuevas ideas "transformistas», podemos constatar que el evolucionismo biológico defendido no se identificaba totalmente con el darwiniano. De acuerdo con su terminología, consideraba que la explicación dada por el sabio inglés de los mecanismos evolutivos era todavía demasiado «mecánica», por la preponderancia que en ella tenía el "atomismo». Pero la crítica fundamental se centrará en la deficiente explicación que a su juicio daba Darwin al problema de la herencia (González de Linares: 1877a; 1878a; 1879b) ${ }^{1}$. Detengámonos un poco más en esta relación.

En el marco de los acerados debates que se sucedieron en el periodo inmediatamente anterior a la Restauración, coincidiendo con el Sexenio democrático, la postura de nuestro naturalista se situó inequívocamente del lado de las nuevas ideas transformistas, que propugnaban la evolución general de los seres vivos a lo largo del tiempo, a partir de formas anteriores que habrían ido dando lugar a sucesivas transformaciones hasta alcanzar el grado de diferenciación específica de los animales y plantas. Como sabemos, esta propuesta, que gozaba de una aceptación relativa, distaba de ser nueva, pues nada menos que sus primeros esbo- zos ya aparecen recogidos en los escasos fragmentos que se conservan del filósofo Anaximandro, que vivió en el siglo VI antes de nuestra era. Como un Guadiana, la idea de evolución apareció y se ocultó a lo largo de la historia del pensamiento europeo, hasta que en el transcurso del siglo XIX emergió definitivamente, abriéndose camino en todos los órdenes de la vida y en la mayoría de los campos del pensamiento, tanto en el conocimiento de la naturaleza, como en la comprensión de los fenómenos sociales.

El problema radicaba en cómo explicar el fenómeno de la evolución de las especies. La publicación de On the Origin of Species en 1859 contribuyó, entre otras cosas, o orillar la aportación lamarckiana, que había ido ganando una cierta aceptación entre los naturalistas en la primera mitad del siglo, de manera que la segunda parte del mismo fue haciéndose paulatinamente adepta al darwinismo, pero adoptando muchos matices, que discurrirían a través de un espectro -y las polémicas que recoge el caso español son en esto elocuentes - marcado por el abrazo sin reservas de la nueva teoría, hasta por su aceptación crítica, como fue el caso de González de Linares.

La grandeza de la propuesta darwiniana lograba conjugar con habilidad estos tres tipos de recursos: a) abrumadora aportación de evidencias obtenidas tras largos años de paciente investigación recogidas en estudios de campo; b) sensibilidad para conectar con el ambiente intelectual del momento, caracterizado por el peso del individualismo, de la idea de progreso, del malthusianismo, y, por descontado, del paradigma evolucionista; c) introducción de un sencillo mecanismo biológico como fue el de la selección natural - por analogía con la labor selectiva practicada por los criadores de ganado- para explicar que las variaciones que se preservan en el transcurso de la evolución lo hacen por ser las más beneficiosas para el organismo en su proceso de adaptación al medio. Como pone de relieve la siguiente cita, que procede de un artículo escrito por González de Linares veinte años después de la publicación de la obra emblemática del naturalista británico - artículo sobre el que tendremos que volver-, lo que entusiasmó de la propuesta darwiniana, más que las pruebas que aportaba, fue el carácter unitario de la teoría, que podía presentarse como la más conforme con la razón y a la naturaleza. Así se expresa:

Nadie ignora con qué entusiasmo fue recibida, en general, salva la repugnancia que sintieron en un principio los naturalistas más adictos a la tradición, la teoría mecánica de Darwin sobre la unidad de origen de los diversos organismos que pueblan la tierra. A la vuelta de algunos años de encarnizada lucha entre el antiguo principio de la absoluta fijeza de las especies, esto es, de la diversidad primordial de las formas orgánicas, y la hipótesis nueva, que las unifica á toda ellas al asig- 
narles una misma procedencia, al suponerlas evoluciones sucesivas de un solo tipo elemental, metamórfosis de una forma primitiva y simplicísima, triunfó, á la postre, el nuevo principio, y se impuso de lleno á naturalistas y filósofos. Al parecer, porque vinieron á confirmarlo más y más cada día observaciones ulteriores, nuevos hechos desconocidos antes; si bien es tan difícil, tan imposible acaso, probar hoy en el terreno experimental la verdad del proceso trasformista, como pudo serlo á raíz de la publicación misma del libro de Darwin. En realidad, (y sin darse cuenta de ello los diversos pensadores), porque fueron reconociendo poco á poco en la intimidad secreta de su pensamiento, que la nueva idea era en sí misma mucho más unitaria, más racional, más adecuada a las exigencias de nuestra razón, más conforme, por lo tanto, á la Naturaleza misma, que el antiguo dogma, incapaz de satisfacer con su variedad primitiva é irreductible de formas orgánicas la aspiración á la unidad ingénita en el espíritu humano, obligado a reflejar en sí mismo el organismo universal que forma la complexión entera de las cosas (González de Linares, 1879b, pp. 479-480). ${ }^{2}$

Años después, en sendos artículos publicados en $1884^{3}$ y 1885 respectivamente, volverá a elogiar el talento de Darwin por saber interpretar los hallazgos de algunos sabios alemanes a finales del siglo XVIII sobre la intervención de los insectos en la reproducción de las plantas. Nuevamente, más que los descubrimientos propios sobre la fecundación de las orquídeas y los redescubrimientos de antecedentes literarios, será el potencial de la teoría lo que suscite la admiración de nuestro naturalista, cuando escribe:

No es la novedad de los datos, ni aún la riqueza de interesantes pormenores, lo que ha llevado á los naturalistas contemporáneos á conceder al libro de Darwin la atención que negaron al de Sprengel. El alcance mismo que en él se designa á los fenómenos, la trascendencia teórica que se les reconoce, es lo que en realidad ha determinado la favorable acogida y extraordinario influjo de este libro que, por lo demás, atendiendo solo á los fenómenos que en él se relatan, no sobrepuja mucho a la que dejaron pasar inadvertido los contemporáneos de Sprengel (González de Linares, 1885, pp. 201-202).

Pero como hemos prometido, volvamos al artículo anterior, un largo texto publicado en dos entregas, titulado "La Geometría y la Morfología da la Naturaleza", aparecido en 1877 y 1879. Antes de llegar a Darwin, pero en este caso con propósitos críticos, el naturalista montañés se embarca en una serie de cuestiones especulativas que tienen que ver con el espacio ${ }^{4}$ y la forma que adoptan los cuerpos naturales, tratando de descubrir alguna estructura geométrica en la naturaleza, un interés teórico, propio de quien tenía en gran estima a la ciencia geológica, como fue el caso nuestro autor, que lo conjugó con su dedicación a la cristalografía en su etapa de profesor en la universidad compostelana ${ }^{5}$. Volvamos ya a Darwin.
La admiración que despierta en González de Linares la obra del naturalista inglés no implica una rendida adhesión al darwinismo, en toda la extensión de sus propuestas, lo que no fue ninguna excepción entre los naturalistas de su generación, tanto europeos como españoles. La convicción de que la obra de Darwin ofrecía la llave para franquear la puerta que permitiese acomodarnos en la estancia desde la que resolver el problema de la evolución de las especies, convivía con la sensación de que dicho lugar estaba poblado de luces y sombras. Ambas actitudes estaban en el ambiente, pues junto a las grandes certezas que la teoría suministraba, no eran de escaso relieve las incertidumbres que acumulaba.

Por lo que a González de Linares se refiere, hemos anticipado más arriba el núcleo de su crítica: la propuesta darwiniana incluía una explicación «mecanicista», cuya causa estaba en otorgar un protagonismo desmesurado al medio -o al "clima», como dice nuestro autor-, en detrimento del papel relevante que, según él, juega la herencia. Hablar de cómo se transmite la herencia, por aquellos años, era adentrase en aguas procelosas y llenas de peligros, con el consabido riesgo de naufragar, tarea para la que tanto Darwin como el propio González de Linares carecían de los conocimientos adecuados, en poder ya de los biólogos de las generaciones venideras. Sin embargo, como no es nuestra intención hacer una «reconstrucción racional» de este episodio, sino solo histórica, tenemos que plantear las condiciones bajo las cuales se podía discutir de este asunto, desde el saber entonces disponible ${ }^{6}$, además de ofrecer noticia de las divergencias.

A partir de dichos conocimientos, González de Linares reprocha a Darwin que presente la herencia como el elemento que conserva o fija los caracteres del individuo, concediendo toda la fuerza de las variaciones al clima. Por el contrario, nuestro autor defiende con énfasis la fuerza, l'elan o el impulso vital que atesora la herencia para la formación y el desarrollo de los organismos. Si la variación no se encontrase ya en la herencia, habría que pensar que todas las formas vitales estaban ya contendidas en un plan desde la eterni$\mathrm{dad}^{7}$, lo que le resulta inadmisible. No tener en cuenta las variaciones que la herencia produce, otorgándole una función exclusiva de fijación, parece a González de Linares una

¡Contradicción peregrina! El fruto más excelso de la Fisiología moderna, el progreso fundamental que le debemos, el resultado más grande y de más alta trascendencia de cuantos ha producido en lo que va de siglo, Haeckel lo dice, y á su vez van unidas las de todos los fisiólogos contemporáneos, es el haber mostrado claramente que, lejos de preexistir los órganos preformados ya en el óvulo reproductor, se desenvuelven, por el contrario, lentamente, unos tras otros; merced 
á un proceso evolutivo, diferenciador, que hace surgir de la masa protoplásmica, indistinta al principio, diferencias cada vez más señaladas, formaciones más y más concretas, especiales, determinadas, oposiciones sucesivas que se potencian en grado ascendente (González de Linares, 1879, p. 93).

Convencido del papel creador y diferenciador de la herencia, nuestro autor fía toda la fuerza del proceso evolutivo a explicaciones de carácter intrínseco al propio organismo, relegando la propuesta darwiniana - que viene desde el exterior, al buscar la novedad de los organismos en causas extrínsecas a los mismos-, a un proceso que descalifica como «atomista» y «mecanicista», totalmente alejado del paradigma vitalista al que encomendaba su trabajo de naturalista. Si Darwin estaba en lo cierto en atribuir un papel relevante al medio como foco de las variaciones, por la introducción del mecanismo biológico conocido como la selección natural —una de las metáforas más potentes de toda la historia de la ciencia-, el naturalista cántabro también lo estaba al señalar las insuficiencias de las indagaciones darwinianas sobre la herencia. Faltaba el segundo mecanismo, el de las mutaciones genéticas, para completar lo que hoy conocemos como teoría sintética de la evolución. Pero en la época de la que estamos hablando nadie estaba en condiciones de llegar a dicho descubrimiento. Faltaban todavía muchos años para ello. ¿Habría visto González de Linares este descubrimiento con buenos ojos al enterarse de que las mutaciones juegan el papel de la variación e introducen la «indeterminación» en el proceso evolutivo, mientras que el rol «determinístico» cae del lado de la selección? Pura ciencia ficción sería buscar una respuesta a esta cuestión. No lo es, sin embargo, puntualizar que la postura de González de Linares parece más difícil de defender cuando se trata de explicar no el desarrollo intraespecífico, sino el proceso interespecífico que da paso a una nueva especie a partir de otra u otras anteriores, en el que la sola herencia parece un mecanismo insuficiente.

Durante el año de 1877, González de Linares, como miembro del cuerpo docente de la Institución Libre de Enseñanza, impartió un ciclo de conferencias sobre la morfología de Haeckel que, a modo de crónicas, se publicarían en su Boletín, desde el 14 de abril al 2 de junio, si bien existe una última aparecida al año siguiente, prometiendo una continuidad que no se produjo. Unos meses después, pero en el mismo año, de forma resumida, vio la luz dicha información en la Revista Europea, contribuyendo con ello a una labor divulgativa del pensamiento del biólogo alemán, cuya obra comenzó a traducirse al castellano a finales de la década de los 70 del siglo XIX, alcanzando una gran difusión (Núñez, 1987, pp. 111-113).

La obra sobre la que se produjo la disertación de González de Linares fue la que, diez años más tarde, sería vertida al castellano con el título de Morfología general de los organismos, por lo que imaginamos que nuestro autor tuvo que trabajar sobre la versión original de la misma ${ }^{8}$. Es significativo que centrara su interés en una figura como la de Haeckel para abordar cuestiones que tenían que ver con el origen de la vida y del universo, en lugar de remontarse a un autor como Darwin, centro de los debates más enconados sobre el evolucionismo. Para explicarlo, además de la concesión que nuestro autor hacía al momento cultural de la España de su tiempo, donde la popularidad del naturalista alemán era superior a la del inglés, habría que tomar en consideración la proximidad epistemológica entre González de Linares y Haeckel. En efecto, se trataba de dos autores -el alemán ya consagrado y el español al comienzo de su carreracuyas aspiraciones teóricas desbordaban el campo estricto de las ciencias biológicas para volar a lomos de especulaciones filosóficas, de porte más omnicomprensivo, capaces de aportar una visión general sobre la Naturaleza y el Universo, como era lo propio de dos pensadores que se reconocían practicando un saber propio de la Filosofía de la Naturaleza, asunto sobre el que volveremos enseguida.

El texto disponible adopta desde el comienzo una retórica informativa hecha por alguien ajeno a nuestro autor, construyendo un relato puntual de sus intervenciones, pero, a medida que se suceden las crónicas y avanza la exposición, va desapareciendo la figura del anónimo reportero y la prosa explicativa parece corresponder al propio González de Linares, que ya no precisa del auxilio de un intermediario que hable en su nombre. En sus intervenciones conjuga el tono expositivo con la evaluación crítica. Aplaude la obra de Haeckel como contribución a la biología de su tiempo y coincide con él en el evolucionismo y el monismo filosófico. Sin embargo, el monismo del español es «naturalista», frente al materialismo del alemán. González de Linares proclama ya en la primera intervención su admiración por los filósofos de la naturaleza y en cierto modo se considera continuador de esa tradición que arranca a finales del siglo XVIII en Alemania y a la que acabamos de referirnos ${ }^{9}$.

El monismo de Haeckel, según la crónica, lo resume del siguiente modo:

Así, materia, forma y fuerza son esencialmente iguales en organismos y séres inorgánicos: son, pues, individuos naturales idénticos en el fondo; no hay dos Naturalezas ante todo; una solo se individualiza luégo en estas formas opuestas. - Tal es la conclusión de Haeckel (González de Linares, 1877c, p. 640).

Este monismo convierte a la materia en el fundamento de lo existente, pues presenta al ser como receptáculo material de donde todo surge y en donde todo se aloja. A juicio de nuestro autor, esta visión no hace justicia a la riqueza del mundo natural, del que 
proporciona un tipo de explicación «mecánica». Si en lugar de este mecanicismo materialista, Haeckel hubiera suscrito el paradigma organicista, en donde la Naturaleza se impone a la Materia, de acuerdo con la misma fuente,

Por este camino, hubiera hallado Haeckel la unidad verdadera, real, de los séres naturales, orgánicos todos, todos vivos, regidos por una misma ley genética y evolutiva, dotados de una misma actividad general, cuyas funciones especiales no son otras, seguramente, que las fuerzas físico-químicas, las mal llamadas fuerzas de la materia (González de Linares, 1877c, p. 779).

En resumen, en un esfuerzo de síntesis, éstos son, según nuestro autor, los siete "pecados capitales» que presenta la Morfología de Haeckel:

1) Confunde en círculo vicioso la Fuerza con el movimiento, pues estima aquella resultado de este, y á éste engendrado por aquella: 2) Limita la Morfología de la Naturaleza á la de la Materia, esto es, á la ciencia del espacio material, olvidando que el tiempo y el movimiento son, como el espacio, formas naturales y sus ciencias respectivas entran en la Morfología natural: 3) Entiende la Química unas veces como ciencia natural en su integridad, y la reputa otras término mediador entre la Morfología y la Foronomia: 4) Hace de la vida un atributo peculiar de una esfera de la Naturaleza, afirmando una supuesta "Abiología» contradicha por las ideas y los hechos: 5) Divide también la ciencia natural en dos partes, telúrica y uránica, como Humboldt, desconociendo la subordinación de la Tierra al reino sidero: 6) Desconoce la identidad de la Geometría y la Morfología natural, pues no hay espacio vacío abstracto, sino lleno siempre de materia y, por lo tanto, sólo una ciencia debe tratarlo: 7) Niega a la Morfología descriptiva carácter de ciencia siguiendo la opinión de todo el idealismo respecto de la Historia, sin atender á que la ciencia exige sólo enlace sistemático, organismo, sea de ideas, sea de hechos (González de Linares, 1877b-1878, p. 39).

\section{OJEADA A LA HISTORIA}

La recepción crítica referida a Darwin y a Haeckel, como hemos podido ver, no la hace solo desde la profesión de científico que ostentaba González de Linares, sino apoyándose en su condición de Filósofo de la Naturaleza, dedicación que hoy no suena como entonces, si es que ahora emite algún sonido reconocible. Pero si actualmente la expresión o el sintagma «Filosofía de la Naturaleza» está en desuso y solo conserva alguna acepción significativa, bien que dotada de una cierta inercia residual, en el ámbito de algunos cultivadores de la filosofía neoescolástica, habiendo sido absorbido su contenido anterior por las diferentes ciencias físico-naturales, no sucedía lo mismo en la segunda mitad del siglo XIX, en la que algunas tradiciones intelectuales, además de cultivadoras de las ciencias de la vida, revindicaban para sí la orientación filosófica volcada conceptualmente sobre la Naturaleza. Ello no significa que todos los científicos del momento, los naturalistas sobre todo, fueran filósofos naturales, pero sí desempeñaron esta función aquellos que, como González de Linares, bebieron en las fuentes del círculo krausista ${ }^{10}$

A partir del siglo XVII el estudio de la naturaleza abrazó el paradigma mecanicista, imponiéndose de forma rutilante desde la autoridad ganada por las obras de sabios como Galileo, Descartes, Kepler, Newton y Laplace, por citar a grandes figuras de la historia de la ciencia. Pero cuando a finales del siglo XVIII y a lo largo de todo el siglo XIX, el mundo de la vida se ofrece a la contemplación científica, son muchas las voces, en Alemania especialmente, de médicos, naturalistas, filósofos y poetas que se rebelan contra la servidumbre que, según ellos, representa enclaustrar la riqueza de la vida dentro del modelo mecanicista hegemónico. Nace entonces lo que se ha dado en llamar, como alternativa, la "ciencia romántica», y la «medicina romántica» - objeto de una creciente curiosidad historiográfica-, que antes de perder definitivamente la guerra libró alguna singular batalla, como la que protagonizara Goethe contra la teoría de los colores de Newton. Durante algún momento cundió la ilusión de estar ante paradigmas rivales, pero no fue más que un espejismo, al que algunos filósofos prestaron su contribución. Sin embargo, el debate no se produjo en balde, a juzgar por algunas de las vías que abrió y que se trocaron en nuevas miradas sobre el mundo natural, capaces de ser aprovechadas siglos más tarde, quizá en este en el que nos hallamos.

A pesar de la denuncia que los cultivadores de la ciencia romántica en su calidad de intérpretes de la naturaleza desde el campo filosófico hacían del paradigma mecanicista, no hay que olvidar, con todo, que la expresión «Filosofía de la Naturaleza» no había desaparecido del vocabulario de los sabios anteriormente citados. Galileo se consideraba un filósofo de la naturaleza - en la estela de lo que en su momento hiciera Aristóteles-, que estaba renovando la concepción de la misma desde bases metódicas nuevas, introduciendo la matemática y el experimento. Newton, como es de sobra conocido, no tuvo empacho en incorporar dicha expresión formando parte del título de su obra principal: Philosophiae naturalis principia mathematica.

González de Linares se vio a si mismo como un filósofo de la naturaleza cuando aspiraba a ir más allá de cualesquiera de las especialidades científicas que cultivó para encontrar un fundamento epistemológico al saber, que respondiera a una visión unitaria del conjunto de los seres naturales, a los que había que categorizar. 
Disponemos de dos informaciones que revelan su interés por las cuestiones relacionadas con la Filosofía de Naturaleza por los años en que su contacto con el krausismo era más intenso. Se trataba de una Filosofía de la Naturaleza tal y como se cultivaba en la Alemania de las postrimerías del siglo XVIII y en la primera mitad del siglo XIX, interesando tanto a escritores románticos como a filósofos idealistas, a cuyos textos pudo acceder directamente nuestro autor por su dominio de la lengua alemana. Sabemos que González de Linares gustaba completar sus explicaciones de Historia Natural en la Universidad de Santiago con aportaciones de Kant, Hegel, Schelling, Oken ${ }^{11}$, Krause, y Carus $^{12}$, todos ellos cultivadores de algún género de filosofía de la naturaleza, cuyo conocimiento exigía con rigor a sus jóvenes alumnos, sin que exista constancia de que la recepción de tales ideas por parte de estos fuera recibida con entusiasmo ${ }^{13}$. Por otra parte, la primera publicación de la que tenemos noticia, que data de 1866, se interesa por la figura de Goethe como naturalista.

En términos muy generales es propio de la Naturphilosophie ${ }^{14}$ presentar a la naturaleza como un todo organizado, cuyos seres obedecen a las mismas leyes, estando caracterizado aquél por su actividad, evolución y dinamismo, en definitiva, concebido como una totalidad "viva», de manera que el paradigma de lo orgánico, de lo vital, acaba imponiéndose como modelo a través del cual se conceptúa el conjunto de todos los seres existentes de cualquier Reino de la Naturaleza ${ }^{15}$.

El filósofo más importante que trató de construir una Philosophie de la Natur desde el humus intelectual proveniente de la Naturphilosophie en el cambio de siglo del XVIII al XIX fue Schelling ${ }^{16}$. Siguiendo la presentación que Arturo Leyte, reconocido especialista en la obra del pensador alemán, hace a la traducción de sus textos de filosofía natural, podríamos conceptuarla a partir de los siguientes pasos. Schelling le da la vuelta a la filosofía trascendental de cuño kantiano y fichteano, descartando que el fundamento filosófico de lo real recaiga del lado del sujeto, pues este mismo requiere un fundamento ulterior - autónomo, desligado, "suelto» o $a b$-soluto-que lo asiente en la riqueza que representa la totalidad del ser. Esa totalidad se encuentra "repartida" entre la naturaleza y el espíritu, formando parte de lo mismo, ya que la naturaleza es condición de la aparición del espíritu. De esta suerte, naturaleza y espíritu son dos polos del decurso unitario del ser, que ya no se define de manera estática, sino como actividad o devenir. En el vocabulario científico del momento, el acercamiento a la naturaleza para presentarla como el gran escenario donde se producen y consuman los procesos, desarrollos, y la evolución de los diferentes fenómenos, de manera que podrían gozar de una tematización a modo de «historia natural», era sinónimo de afirmar una naturaleza con vida, mientras que desde la terminología filosófica había que apurarla con el vocablo espíritu, inserto en el seno de la naturaleza. De esta categorización filosófica resulta que un término tan decisivo para la filosofía moderna en general, y trascendental en particular, como es el de sujeto, experimenta un desplazamiento semántico, al abandonar su exclusiva dimensión epistémica para solaparse en la naturaleza, al entenderse esta como actividad, como movimiento, una de cuyas fases es el conocimiento de la misma ${ }^{17}$.

Además de los filósofos propiamente dichos desempeñaron un papel relevante dentro de esta corriente de pensamiento algunos médicos que elevaron a tesis filosóficas más generales sus conocimientos científicos, sirviendo aquellas de orientación a futuras investigaciones. Tal fue el caso de Oken, seguidor y contradictor de Schelling a la vez, defensor de la evolución general de los organismos a partir de una primordial masa indiferenciada, a la que enmarca en el ámbito de un mundo concebido como una totalidad en la que Dios se va expresando, y de Carus, contemporáneo suyo, también en la órbita de Schelling, quien explica la evolución de la vida como un proceso de diferenciación de lo múltiple, o de individuación de los seres.

De esta suerte, para los krausistas españoles, como nuestro naturalista, la naturaleza en su conjunto se presenta como algo dotado de vida, de manera que todos los elementos, niveles o reinos que la forman son partes solidarias de una organización, constituyendo un «organismo» vivo. Escribe el pensador alemán: "La naturaleza debe ser el espíritu visible, el espíritu la naturaleza invisible» (Schelling, 1996, pp. 110-111).

Esta enfática, a la vez que bella, expresión del filósofo de la naturaleza más importante, procedente de su primer texto sobre esta cuestión, del año 1797, pone a las claras el sentido de lo que venimos sosteniendo en la terminología propia del idealismo: la naturaleza tiene espíritu (Geist), vida, actividad; es sujeto, además de objeto, posee dinamismo, «movimiento». No solo es, sino que deviene, se desarrolla. Al presentarse el conjunto de los seres como una unidad, considerándose el todo como uno, la realidad en su conjunto acaba unificándose en la identidad de naturaleza y espíritu. La naturaleza es la «visibilidad» del espíritu tanto como el espíritu es la «invisibilidad» de la naturaleza.

De una manera más precisa, y en palabras de otro especialista en el filósofo alemán, se puede decir de este modo:

La deducción filosófica configura una sistematización grandiosa en la que naturaleza orgánica y naturaleza inorgánica aparecen formando una unidad en la naturaleza universal. Es una única realidad, el organismo constituido por el todo de la naturaleza, la que, por medio de una y la misma fuerza, produce los fenómenos orgánicos e inorgánicos. 
(...) Del principio de la correspondencia entre funciones orgánicas y grados de la naturaleza inorgánica se infiere que la naturaleza orgánica contiene los fundamentos explicativos de esta última (Pérez, 2003, p. $55 ;$ p. 56).

En esta explicación se pone de manifiesto la analogía y la diferencia entre la posición de Schelling y las teorías evolucionistas que irrumpirían a partir de la segunda mitad el siglo XIX y de las que, no sin polémica, González de Linares se convirtió en uno de sus propagadores.

Parece que la naturaleza ya lo tiene todo in nuce, potencialmente, en lenguaje aristotélico, desde siempre, y que esa riqueza se va desplegando en fases, momentos, seres de diferente factura, pero contando con que es ese todo el que se autoproduce, a modo de la natura naturans, de manera que solo puede devenir lo que ya es, aunque el ser se conciba como devenir. Vista la naturaleza de este modo, predomina la perspectiva del todo sobre las partes. Y si es verdad que el espíritu se esconde en la naturaleza, entonces hay vida en todo desde siempre, de donde se sigue que el mundo inorgánico se presenta no como el preludio que prepara lo orgánico, sino como lo orgánico extinguido, muerto.

Para una especulación sobre la Naturaleza como la que hemos bosquejado, puede servir de rótulo, al menos esta doble caracterización: lo real es uno y se identifica con la naturaleza, lo que da lugar a un monismo naturalista, y la naturaleza es esencialmente activa, y ello habla del dinamicismo de lo real. Quien vive inserto en este tipo de Weltanchsaunng está en una posición intelectual receptiva por la permeabilidad que ofrece esta visión al modelo evolucionista que se aproxima, como si la episteme románticoidealista anteriormente dibujada indujera a aceptar la existencia, casi sin solución de continuidad, de un planeta como la tierra, escenario de cambios diversos, y de unas plantas y animales, objeto de diversas transformaciones. No tiene esta hipótesis rango de teoría, pues no en todos los casos fue así, pero sí de reconstrucción racional, de manera que lo que sucedió a bastantes intelectuales krausistas, como el caso de González de Linares, era lógico, además, que sucediera, aunque no todos los naturalistas de su tiempo se adhiriesen al nuevo modelo teórico evolucionista, un modelo que estaba removiendo los cimientos de la biología contemporánea bajo el signo de la «transformación» (Coleman, 1971, pp. 100-155).

\section{CUESTIONES ONTOLÓGICAS}

En 1878, el año de su mayor fecundidad publicística, Augusto González de Linares pronunció otra conferencia en la Institución Libre de Enseñanza, que después vio la luz ese mismo año, en forma de artículo, en dos publicaciones diferentes, y también como separata o folleto independiente. En sendos casos el texto publicado excedía con creces lo expuesto oralmente. Su título, La vida de los astros, obra que hemos tenido ocasión de reeditar con ocasión del primer centenario del fallecimiento de su autor (González de Linares, 2004).

La tesis que se defiende en este texto -que contiene un conjunto de aportaciones diversas procedentes de la biología celular, de la historia de la ciencia, con especial referencia a la astronomía, así como de la filosofía en su consideración como un ontología del ser natural- viene a concluir que los astros son seres vivos, como las células, argumentándolo mediante la aplicación a los mismos de las funciones propias de la vida, ello es, la nutrición, la reproducción y el movimiento. Sin entrar en los detalles de la propuesta, el marco teórico en que se sitúa esta conjetura destila una filosofía de carácter vitalista que envuelve y unifica todo lo real ${ }^{18}$. Detengámonos en una reflexión estampada al final del texto, que a modo de resumen expresa lo que apuntamos. Escribe nuestro autor:

Fuerza será reconocer que son los minerales y demás cuerpos inorgánicos, productos, resíduos de la tierra y demás astros y de los restantes organismos, partes, concreciones sólo de su materia respectiva; de ningún modo seres verdaderos, unidades naturales: que las fuerzas generales de la materia son puras manifestaciones de la fuerza misma de la vida, única en toda la naturaleza, su actividad general, capaz de determinarse luego en fuerzas especiales diversas, gravedad, luz, calor, afinidad, etc.

Ante lo cual deja de ser problema serio el del orígen de la vida, eterna y única realidad del mundo físico.

La misma actividad que engendra el organismo sidéreo, hace brotar en él, llegada la ocasión oportuna, los organismos fitozoicos y humanos. No hay ya que discutir sobre generaciones espontáneas. Hay verdadera homogenia; la vida brota de la vida. El universo todo se organiza: ya tiene en sí mismo el principio inmediato de su propia existencia; ya se elabora á sí propio, si vale la palabra; el mismo educe eternamente de su unidad esencial la variedad infinita de organismos en que está siempre determinada aqueIla. El cielo deja de ser el piélago inmenso del vacío, el recipiente del mundo; llénase de vida todo él; es, en suma, el universo mismo. Y universo y cielo á la vez se unifican con la Naturaleza, y desaparecen totalmente las grandes abstracciones latentes en los conceptos que simbolizan estos nombres (González de Linares, 2004, pp. 223-224)

Pese a la extensión de esta cita, vale la pena demorarse en algunas de sus tesis, las cuales revelan toda una filosofía de la naturaleza enunciada de manera categórica $^{19}$, como ya hemos visto, que se orienta por el principio funcional, denominado por Carus la "ley del todo en las partes», y que se expresa como sigue $^{20}$ : 
[...] admitimos en la Naturaleza un enlace, cuya expresión puede ser esta: «el estado de cada ser natural repercute en el de todos los infinitos restantes; toda la Naturaleza se siente, en su infinitud, del estado de uno de sus puntos infinitésimos; toda la Naturaleza se condiciona interiormente en cada momento por el estado de cada uno de sus séres». E inversamente: «cada sér natural recibe en cada momento el influjo del estado total de la Naturaleza restante. El estado, en cada caso, de un sér natural, se condiciona en cuanto á su modalidad, por el de la total Naturaleza restante» (González de Linares, 1879c, p. 98).

Para quien esté algo familiarizado con la historia del pensamiento filosófico no le será difícil escuchar cómo resuenan ciertas voces del pasado, a veces tan lejano, como el que se remonta a los orígenes del pensamiento filosófico, recogidas en los fragmentos que conservamos de los presocráticos. Pues la tesis de un mundo animado por fuerzas vitales, que se autoengendra o autoproduce recorre buena parte de la historia de la filosofía, desde un cierto neoplatonismo hasta el Renacimiento, con Giordano Bruno a la cabeza, pasando por la consideración de la naturaleza como natura naturans, de acuerdo con los comentarios que Averroes efectuó a los libros de física de Aristóteles y sus desarrollos posteriores en la escolástica medieval.

Este hilo rojo del naturalismo vitalista, con sus derivas hacia alguna orientación de carácter místico, se anuda, a través de la filosofía de Spinoza y buena parte del pensamiento kantiano sobre el asunto ${ }^{21}$, con el romanticismo, el idealismo y la Naturphilosphie, a la que antes hemos hecho referencia, y no es ajeno al vitalismo filosófico decimonónico en alguna de sus muchas variantes. Nuestro autor llega a semejantes conclusiones recorriendo el camino hacia la biología experimental desde el marco teórico interpretativo que implica su asimilación del krausismo, exponente de este aroma intelectual, bajo el cual quedan a cubierto sus indagaciones sobre la teoría celular. Monismo naturalista y vitalista, esa es la idea.

Monismo, porque lo real se reduce a una única entidad en la que todo cabe, de donde todo procede, aunque se despliegue en variedades de seres individuales. Se repudian tanto visiones «pluralistas» como «dualistas».

Naturalista, porque esa entidad única es la Naturaleza. González de Linares podría haber adjetivado -en el caso de hacerlo- su monismo como "materialista», y en tal supuesto el ser único sería calificado como material. Pero semejante operación no cabía dentro de sus planteamientos, por cuanto, a tenor de los mismos: (a) lo material quedaba identificado con lo mecánico; (b) la Naturaleza, frente a la Materia, cabía conjeturarla como algo vivo.

Vitalista, porque todo lo que existe tiene vida, y la vida está ahí desde siempre ${ }^{22}$.
Pero las inquietudes de González de Linares como filósofo de la naturaleza no iban a finalizar aquí, pues se reservaba el remate de algunos otros intereses que recorren el conjunto de su obra desde los años setenta hasta 1893, al menos. El primero de ellos al que queremos referirnos, profundizando en un principio sobre el que anteriormente hemos llamado la atención, se esfuerza por ofrecer una serie de consideraciones acerca de la unidad de la naturaleza y la interdependencia de todos los seres, en un artículo que lleva el significativo título de «El parentesco genealógico y el supuesto ideal en la naturaleza», expresándose en los siguientes términos:

La continuidad de la Naturaleza entera, la concreción unitaria de toda ella en cada uno de los individuos, parece exigir que la afinidad entre estos no sea parentesco ideal abstracto, sino ideal-real, esto es, genealógico. Cada individuo natural es genéticamente pariente de todos los demás. Lo ideal, en la Naturaleza, debe serlo al modo natural mismo: si la Naturaleza es totalidad, concreción, continuidad, continuo, concreto, genealógico debe ser lo ideal en ella (González de Linares, 1892a, p. 283)

Aunque desde el punto de vista analítico el filósofo natural distingue claramente entre el plano real e ideal, en un segundo momento los unifica en tanto que la teoría debe seguir la estructura de la cosa, identificándose con ella, lo que parece un reflejo de la deuda filosófica que nuestro autor tenía contraída con el idealismo alemán.

El segundo foco de atención, fruto de dos artículos diferentes, renueva su interés por el carácter individual de los seres naturales, como una condición de la vida, conceptuando a los individuos como totalidades organizadas (González de Linares, 1891; 1892b), mientras que el tercero se enfrenta nuevamente con las cuestiones relacionadas con el espacio. Si la naturaleza - viene a decir nuestro filósofo- tiene su geometría, ello significa que aquella no puede entenderse sin la unión de materia y espacio. Pero si, como acabamos de comprobar, la naturaleza es un continuo donde evolucionan los distintos seres, la materia va unida al espacio y al tiempo, sin vacíos, pero tampoco sin rupturas, siendo espacio y tiempo las formas de la multiplicidad $^{23}$.

Embarcado ya en investigaciones más propias de la biología marina, será el año 1891 una de las últimas ocasiones en las que nuestro autor ofrezca al público una reflexión mediante la que seguir reclamando la colaboración imprescindible entre ciencia y filosofía que, en su caso, viene exigida por la necesidad de establecer un concepto de individuo natural que se distancie del atomismo imperante y se enfoque desde una perspectiva que implique un compromiso intelectual de carácter holístico. Escribe así: 
Hasta tanto que empiece á prepararse siquiera su resolución ulterior por obra simultánea de la ciencia natural y la filosofía, cuyo criterio es hoy tan radicalmente diverso; mientras no lleguen una y otra á influirse y se haga posible ascender de los hechos á las ideas, de los conceptos reinantes al concepto filosófico, y descender de este, que subsiste inmutable á través de los diversos estados de cultura, á la expresión de que debe actualizarse en el momento presente, atendidos los fenómenos que conocemos y el enlace causal que entre sí nos ofrecen; hasta que inicien, asociados empíricos y pensadores esta nueva tendencia que se impone más y más cada día, ¿puede acaso intentarse solución alguna, sin riesgo positivo, inminente, seguro, de torpes confusiones é irracionales paralelos? (González de Linares, 1891, 338, p. 78) ${ }^{24}$

\section{HACIA LA EPISTEMOLOGÍA}

Si en lo que nos hemos detenido hasta el momento, referido a la Filosofía natural de nuestro naturalista, concierne a cuestiones de carácter histórico y sistemático, hay un asunto, de orientación esencialmente metodológica, que encaja también en su Filosofía de la Naturaleza, concebida como Filosofía de la ciencia. Se trata de cuestiones de índole epistemológica que tienen que ver con criterios de demarcación y clasificación la las ciencias, referidos en este caso a la Ciencia Naturales.

Por lo que atañe a la epistemología de la ciencia, González de Linares es de los escasos naturalistas del momento que denuncian el abismo - el «divorcio» en sus palabras - que poco a poco se va abriendo entre la filosofía y las ciencias, y lo hará en un amplio artículo de 1873 titulado Ensayo de un introducción al estudio de la Historia Natural, que apareció al año siguiente, según la costumbre de la época, en forma de folleto, y que, en su primera parte, contiene la totalidad de la Tesis doctoral de nuestro naturalista, titulada Concepto y relaciones de la Historia Natural (González de Linares, 1874, pp. 17-40). Es sintomático del valor que los institucionistas prestaron a este texto, que el Boletín de la Institución Libre de Enseñanza lo reeditó en 1905, un año después de la muerte de su autor. Y estaban en lo cierto, pues se trataba de la más elaborada de las reflexiones epistemológicas de cuantas salieron de la pluma, tanto de filósofos, como de científicos ligados al krausismo en España.

Esta suerte de crítica de la razón experimental reclama una nueva "doctrina de la ciencia» que unifique el conocimiento como réplica a la unidad de la realidad, aportando los principios que actúen como propedéutica del conocimiento científico. La relación entre las ciencias y la filosofía la juzga González de Linares tan pertinente que sin las aportaciones del pensamiento filosófico serían ininteligibles tanto la unidad de las ciencias físicas, como el evolucionismo de los organismos (González de Linares, 1874, p. 23).
El trabajo es tributario del momento histórico que atravesaba esta parcela del conocimiento científico, caracterizada, entre otras cosas, por la necesidad de asentar las diversas disciplinas, buscando la identidad que permitiera establecer las diferencias en el concierto general de las ciencias, en un panorama perturbado, además, por la aparición y progresiva consolidación del paradigma evolucionista, y sobredeterminado por la presencia de interpretaciones filosóficas rivales. Lo más significativo de dicho enfrentamiento se observa en las diferencias existentes entre el idealismo que decae y el positivismo que nace. Aquel se instala en el a priori de la idea, mientras que este se atiene a la constancia del dato. En esa controversia, parece que nuestro autor, al menos en este momento, quiere integrar «la idea y el hecho». En su conjunto el texto lamenta la desvinculación entre ciencia y filosofía.

Algunas reflexiones de González de Linares son las siguientes:

a) Es necesario construir una «Doctrina de la Ciencia»-expresión de resonancias terminológicas fichteanas, pero no de contenido- para solventar el problema que implica la contradicción entre la unidad de la realidad y la dispersión del conocimiento.

b) La doctrina o teoría de la ciencia debería contener una serie de principios, conceptos y relaciones que sirvieran de prólogo o "propedéutica» a cada ciencia en particular. De esta manera la unidad de la realidad vendría a ser conocida y explicada mediante procedimientos teóricos comunes.

c) La crítica del estado actual de la Historia Natural puede resumirse de este modo:

[...] consiste sin duda en la oscuridad reinante acerca de su contenido. Ciencia eminentemente experimental, como no puede ménos de serlo, refleja á cada paso en la contínua mudanza de su desarrollo la incesante novedad propia del dato sensible; y divorciada en mal hora (divorcio que se explica fácilmente, pero que es difícil legitimar) de la indagación filosófica, teniéndola por estéril y aún perjudicial á veces, ha llegado á cobrar verdadera repugnancia al rigor científico, sin poder presentar en realidad otra cosa que una mera compilación, más o menos informe, de observaciones y experimentos aislados, ajenos á las más elementales exigencias de la exposición didáctica, y hasta á los más sencillos preceptos de la Lógica (González de Linares, 1874, p. 18). 
d) El concepto de una ciencia como la Historia Natural se completa con la aparición de la perspectiva evolucionista y del punto de vista genético aplicado a la formación y desarrollo de los seres naturales en el tiempo, de manera que las categorías naturalistas se funden con las historicistas.

e) El evolucionismo tiene raíces filosóficas, según se nos dice en el siguiente paso:

Baste notar que, sin conocimiento filosófico, jamás hubiera podido formarse ciencia alguna de la Naturaleza, necesitada como está y estará eternamente la experiencia de antecedentes y supuestos puros de razón, que así guían al zoólogo como al físico, al químico y al astrónomo, al geólogo y al botánico, á cuantos cultivan, en suma, alguna esfera en este orden de realidad. La unidad de las fuerzas, en la Física; las cuestiones sobre el origen y evolución de los organismos terrestres, en la Historia Natural, pueden reputarse como las dos señales culminantes de una tendencia marcadamente filosófica en las Ciencias de la Naturaleza, aunque por desgracia, todavía harto vaga é incompleta, y desatendida por los demás (González de Linares, 1874, p. 23).

f) La Naturaleza se conceptúa como un todo, principio, raíz y razón del conjunto de los seres, engendrados en función de su capacidad infinita, según un plan providencial - de acuerdo con el "panenteísmo" procedente de Krause, esto es, según la idea de que, sin identificar a Dios con el mundo, como sucede en el panteísmo, el mundo está «en» Dios-. A la postre se recurre para una explicación de este tipo a la distinción spinoziana entre natura naturans y natura naturata.

g) La continuidad natural de la especie humana con especies animales anteriores se complementa con una visión diferencial, cuando se postula la existencia de un nuevo tipo de ser o reino, propio del ser humano, el reino «hominal» (sic).

\section{A MODO DE CONCLUSIÓN}

El programa de investigación de carácter epistemológico que González de Linares esboza en sus años de profesor universitario en Santiago de Compostela que tenía sus analogías con el esfuerzo por buscar enlaces entre las diferentes ciencias, planteado por aquellos años en Alemania (Helmholtz, 1876)-, queda sin desarrollar, dependiente tanto del proyecto kantiano de 1786, los Principios metafísicos de la ciencia natu$\mathrm{ra}^{25}$, como del propio Krause. A ello habrían contribui- do tanto causas de orden externo como interno. Por una parte, la cuestión universitaria de 1875 enfrentó a los krausistas con su propia realidad. Ellos mismos, profesores separados de la función pública, encontrarían un nuevo medio de vida poniendo en práctica sus ideales pedagógicos con la fundación de la Institución Libre de Enseñanza. Por otra, para esas fechas, el desarrollo metafísico del krausismo español estaba prácticamente agotado. Apenas habían aparecido, en el campo de la teoría, nuevas ideas después de las aportaciones poco originales de Julián Sanz del Río, expuestas con frecuencia en un castellano difícil, cuando no abstruso, rayando en ocasiones en lo críptico.

Puede afirmarse que el horizonte teórico en que se desenvolvió la actividad científica de este naturalista fue el sincretismo idealista propio del krausismo, lo que significaba ser fiel tanto al dato empírico como a la idea. Como hemos tenido ocasión de subrayar en otros trabajos, la recepción del positivismo, que junto con el neokantismo, fueron paulatinamente reemplazando al krausismo en la España de la Restauración, hasta dar lugar a lo que, con mayor o menor fortuna se llamara "Krauso-positivismo» (Posada, 1892, 358, p. 4), no afectó, o afectó solo tangencialmente, a González de Linares, quien no tenía en gran aprecio las aportaciones de los filósofos positivistas por su escaso vuelo teórico, y juzgaba que lo que podían aportar ya se lo daban las ciencias que cultivó ${ }^{26}$.

Pero el designio del movimiento krausista iba a desplazarse y conservarse - a modo de una Aufhebungpor otros ámbitos de naturaleza más aplicada y menos especulativa, como fueron los de la educación, llevando los objetivos del imperativo de la ciencia hasta su ideario programático. La vinculación entre el valor de la ciencia y el deber de su enseñanza se encuentra ya expuesta en un artículo de González de Linares del año 1875 , formando parte de un proyecto de carácter epistemológico y pedagógico, consistente en teorizar sobre las fuentes y la enseñanza de la Historia Natural. Concediendo un tratamiento absoluto y un valor intemporal a la verdad científica, cuya adquisición, sin embargo, viene a ser obra de la historia, nuestro autor establece un nexo estructural entre la producción y la comunicación del conocimiento. Así se expresa:

La ciencia, que en sí misma existe eternamente formada, como el sistema absoluto de la verdad, no es para el hombre sino una obra temporal y progresiva, que mediante su actividad, desplegada en la aplicación reflexiva, ordenada, artística de todas sus facultades, y especialmente de las intelectuales ó del pensamiento, va laboriosamente conquistando en un proceso difícil, en el cual los individuos y áun los pueblos se auxilian unos á otros, para extender en el mundo los beneficios del conocimiento y de su luz, maestra de la vida. [...]

Ahora, la construcción de la ciencia como obra de la actividad humana, y obra tanto individual como so- 
cial, consta de dos funciones: la investigación de la verdad y su comunicación por parte del investigador á los demás hombres: la indagación y la enseñanza, la heurística y la didáctica, como suelen también denominar los lógicos (González de Linares, 1875, pp. 271-272).

La personalidad intelectual de Augusto González de Linares hay que juzgarla en su conjunto, sumando sus contribuciones científicas a sus aportaciones filosóficas, aún si el resultado respira un cierto aire «he- terodoxo». El naturalista cántabro fue quizá uno de los últimos pensadores en lamentar los errores a que conducía el divorcio entre ciencia y filosofía, y el primero de su generación en vindicar con fuerza un marco epistemológico de naturaleza filosófica con el que legitimar y ubicar a cada una de las especialidades científicas. Pero después de él, el tiempo de la cultura filosófica como base de las ciencias pasó literalmente, no diré si con fortuna, a la historia.

\section{NOTAS}

1 En una serie de cuartillas procedentes del Fondo depositado en la Real Academia de la Historia [RAH], agrupadas bajo la denominación de "Transformismo. Sobre el carácter inmanente de la selección natural», dice textualmente lo siguiente: "Teoría genealógica: Sus fases: 1) Afirmación del lazo genético que une á los diversos organismos, surgidos de la transformación gradual de unos en otros. Lamark. 2) Fundamentación mecánica de este proceso, explicación de una causa eficiente: la selección natural, que en la batalla por la vida permite reproducirse a los mejor adaptados, y entonces se fijan hereditariamente los caracteres además de adaptarse al medio el organismo engendrado, adquiriendo por lo tanto caracteres nuevos» ([RAH], Madrid. Fondo: Institución Libre de Enseñanza, Subfondo «Augusto González de Linares» [AGL]: Caja 129, carpeta 1853).

2 En las citas se mantiene la ortografía del siglo XIX.

3 «Presentir esta ley biológica ha sido el mérito de Darwin, que, instigado, no por los hechos inmediatamente, como él mismo supone, sino por verdaderas exigencias ideales, fáciles de mostrar en la ocasión presente, buscó los fenómenos con observaciones asíduas y precisas, y consiguió tan asombrosos resultados, que hay pocos ejemplos de una revolución tan radical y pronta como la producida en la Botánica con la aparición de su libro Sobre la fecundación de las Orquídeas» (González de Linares, 1884, p. 369).

4 Se trata de una preocupación que aparece en otras publicaciones (véase González de Linares, 1878c; 1890).

5 En la obra de Lorenz Oken - una figura que interesará profundamente a nuestro autor, como diremos en su momento-, titulada Filosofía de la naturaleza, de la que recientemente se han traducido 66 breves aforismos, adquieren una importancia decisiva las matemáticas, al punto de dedicarle una Sección entera que va del aforismo 31 al 40. Veamos esta cita: «4. El espíritu es el movimiento de las ideas matemáticas. 5. La naturaleza es la manifestación de las ideas matemáticas. [...] 7. La Filosofía de la Naturaleza es la representación de las manifestaciones de las ideas en la consciencia» (en Montiel, 1997, p. 89). La tesis de que el mundo natural se explica por la idea o las ideas, y que estas pueden interpretarse more matemático, es tan antigua como la filosofía de Platón. Pero el platonismo matemático que parecen destilar estos aforismos cobra aquí el giro que puede darle el verse inserto en la órbita del idealismo alemán del siglo XIX.

6 Como es conocido, los estudios sobre la herencia genética comenzaron en entrar "en el verdadero camino de la ciencia» - si se nos permite el anacronismo que es utilizar la frase con la que Kant expresaba el objetivo que debiera alcanzar la metafísicagracias a los experimentos que realizó Gregor Mendel sobre la hibridación de las plantas, cuyos descubrimientos, más que dar a la luz, casi enterró, en 1866, en las Actas de la Sociedad de Historia Natural de Brno, - tras haberlos presentado en sesiones correspondientes el año anterior -, y que la comunidad científica, o no se enteró, o si logró tener noticia de los mismos no les prestó la menor atención, hasta que Hugo de Vries, entre otros, los redescubrió en 1900, publicándoles en inglés al año siguiente. González de Linares jamás cita al sabio austriaco, especulándose si Darwin tuvo o no acceso a sus descubrimientos, en todo caso nunca antes de 1859 , año en que apareció On the Origin, pero al que tampoco cita en obras posteriores. (Véase Mendel, G. (1866), "Versuche über Plflanzenhybriden", Verhandlungen des naturforschenden Vereines in Brünn, Bd. VI, für das Jahr 1865, Abhandlungen, pp. 3-47).

7 Escribe nuestro autor: «en una palabra, que es un error la supuesta preformación de los gérmenes, contradicha por la experiencia y opuesta á la idea, la cual repugna concebir el mundo como grandioso mecanismo fabricado todo él de una vez por todas por las manos del Supremo Hacedor; que no hay semejante prexistencia, soñada por los naturalistas bajo el influjo de un misticismo candoroso, empeñando en ver ya en el cuerpo de Adam los de todos los hombres ulteriores, para dar así solución satisfactoria al célebre dogma del pecado original» (González de Linares, 1879b, p. 193).

8 Véase Haeckel, E., Generelle Morphologie der Organismen : allgemeine Grundzüge der organischen Formen-Wissenschaft, mechanisch begründet durch die von C. Darwin reformirte Decendenz-Theorie, Berlín, 1866. Véase Morfología general de los organismos, 1887, de Ernst Haeckel, traducción de Sanpere y Miquel para la editorial Blas Cabrera y Compañía de Barcelona.

9 El propio Haeckel también se tiene por continuador de una corriente de pensamiento entre cuyos antecedentes reconoce a Goethe, Lamarck y, por supuesto, a Darwin (Haeckel, 1887, p. XXVI). Sin embargo, la diferencia más notable con González de Linares estriba en la escasa valoración que le merecen tres $\mathrm{Na}$ turphilosophen alemanes de la primera mitad del siglo XIX como Oken, Schelling y Carus, por la extravagancia a la que conducen 
sus especulaciones teóricas, poco atentas al devenir de los hechos, siendo así que por estos pensadores nuestro naturalista mantenía todavía su aprecio (Haeckel, 1887, p. 76).

10 Y no solo él, aunque, como tendremos ocasión de mostrar, nuestro autor fuera el filósofo de la naturaleza más importante del krausismo español. También lo fueron otros, como el geólogo Salvador Calderón y el físico-químico Enrique Serrano y Fatigati (véase, a título de ejemplo: Serrano \& Calderón, Estudios de Filosofía Natural. Total Organización de la materia, Imprenta M. Tello, 1870). Para una aproximación a esta cuestión que ocupa un lugar singular en la historia intelectual de la España de la Restauración, pueden verse los trabajos de: Jiménez-Landi (1987, II.2, pp. 682-691); Simó Ruescas (2004; 2011).

11 Sobre la figura del médico y filósofo Lorenz Oken pueden verse dos trabajos del investigador Luis Montiel. El primero de ellos incluye la presentación y traducción de un parte de su Lehrbuch der Naturphilosphie, 1843 (Montiel, 1997), mientras que el segundo nos ofrece un estudio más amplio de este autor en el marco de la ciencia romántica alemana de la primera mitad del siglo XIX (Montiel, 1999).

12 Entre la documentación existente en el Fondo de la ILE depositada en la RAH se encuentran tres manuscritos formando tres cuadernillos en octavo a doble cara, de letra muy menuda, con la traducción parcial, probablemente destinada para el uso de Giner de los Ríos, de las siguientes obras: H.F. Leonhardi, Die Characeen (Las charáceas), 15 pliegos; Oken, Naturphilosophie (incluye fragmentos de Botánica), 13 pliegos; Carus, Natur und Idee, 30 pliegos (Subfondo GR, RAH: Caja 38, carpeta 376).

13 En la misma documentación se halla una Bibliografía de Historia Natural, apartado "Filosofía de la Naturaleza en general", que incluye las siguientes referencias: E. Kant, Metaphysische Anfanggründe der Naturwissenschaft, 1786 (Principios elementales metafísicos de ciencia de la naturtaleza, ed. de Leipzig de 1838). Schelling, Von der Weltseele (Del alma del mundo, 1798. Schelling, Aphorismen zur Einleitung in die Naturphilosphie (Aforismos preliminares de la Filosofía de la naturaleza). Oken, Lehrbuch der Naturphilosophie (Doctrina de Filosofía de Ia Naturaleza), Zurich, 1843. C. G. Carus, Idee und Natur (Idea y Naturaleza), Viena, 1861. Hegel. C. C. F. Krause. H. Martin, Philosophie spiritualiste de la Nature (Filosofía espiritualista de la naturaleza). W. Wherwell, History of scientific ideas. (Historia de las ideas científicas), Londres, ¿1858? (El título primitivo era Filosofía de las ciencias inductivas) (Subfondo AGL, RAH: Caja 28 , carpeta 1846). La vida universitaria y social de nuestro joven profesor debió de transcurrir con dificultades en la entonces levítica ciudad compostelana. Existe una carta dirigida a Giner de los Ríos de fecha 17.11.72 en la que detalla el acoso a que se ve sometido por parte de colegas y autoridades religiosas por su negativa a aceptar recomendaciones en los exámenes; comenta los motes que le dirigen por la rectitud con la que se decide a cumplir su papel de profesor; y hace referencia a la existencia de cartas injuriosas dirigidas por algún estudiante que lo reta en duelo (Faus Sevilla, 1986: 166-172, Carta № 17). Las tres cartas en cuestión se encuentran depositadas en a RAH (Véase Subfondo AGL, RAH: Caja 126, carpeta 1801). Jiménez-Landi sostiene que «Lo que acabó de completar la postura adversa del Claustro santiagués contra Linares fue una cuestión de intereses, que, además, afectaba de rechazo a las familias burguesas de Galicia» (Jiménez-Landi, 1987, II.1, p. 84).

14 Sobre el concepto de evolución en el primer romanticismo alemán, véase Breidbach (1993). Una aproximación a las principa- les figuras de la Naturphilosophie en la Universidad alemana de Jena en la primera mitad del siglo XIX, la podemos encontrar en Jahn (1994). Para un estudio más detallado del concepto de interacción (Wechselwirkund), tan importante en la concepción romántica de la naturaleza, véase Müller (1994).

$15 \mathrm{O}$, como dice un investigador puertorriqueño en un voluminoso estudio de conjunto del movimiento romántico, "La filosofía de la naturaleza romántica tampoco puede pasar sin ese supuesto de la unidad de todo. De él se desprende, a su vez, la fuerza simpática, vitalista o pansiquista que explica la vida del universo y simultáneamente el nexo y la armonía entre todas las cosas y los seres, la indisolubilidad de la vida cósmica, su estructura analógica, concepción del devenir cósmico como una vía de restitución a la unidad perdida» (Tollinchi, I, 1989, p. 440).

16 En algunas investigaciones sobre la introducción del krausismo en España, no es infrecuente preguntarse por qué Sanz del Río, puestos a importar una filosofía de Alemania, no volvió los ojos a Hegel o a Schelling, y se inclinó ante Krause, situado varios escalones por debajo de ambos. Un juicio que destaca los valores que para el desarrollo de la ciencia médica en la España del XIX hubiera supuesto la recepción de Schelling, frente a la Krause, la podemos encontrar en Montiel (1995). Pero por lo que respecta a González de Linares, creemos que encontró compatible la aportación de ambos filósofos idealistas.

17 Concluye Arturo Leyte en la "Introducción" a los textos de Schelling: «En suma, la naturaleza es esta sucesión de niveles de vida, o si se quiere, un organismo que se evidencia, sea cual sea su nivel, como producto en que quedan reunidos la propia naturaleza y la libertad, el espíritu. Tan pronto se rompe este vínculo, la materia aparece impenetrable y sólo se deja explicar mecánicamente, por los efectos, que pueden ser percibidos desde fuera como resultado de causas y efectos y no como dinamismo» (Leyte, en Schelling, 1996, p. 39).

18 La tesis de que la evolución está unida a la vida, al punto de que si un cuerpo, del reino natural que fuere, siguiera un determinado proceso evolutivo significaría que estaba vivo, era defendida también por algunos colegas de González de Linares que se movían dentro del krausoinstitucionismo (Calderón, 1881, p. 15). El propio Salvador Calderón reconoce la autoridad de nuestro naturalista, cuando un poco más abajo escribe: «El profesor Linares, [así era llamado por sus compañeros y amigos] acaso el primero que ha tratado de precisar los términos del problema, busca el punto de partida de la vida planetaria en las nebulosas, que, considera, no como masas caóticas, sino como astros que empiezan a vivir y que se hallan en una fase más tardía que la del sol mismo» (Calderón, 1881, p. 19).

19 Pierre Jobit solo menciona como aportación de González de Linares su pretensión de establecer conexiones entre la filosofía y las ciencias naturales (Jobit, 1936, pp. 96-97).

20 La cita de Carl Gustav Carus que incorpora nuestro autor a su artículo "Sobre el criterio actual de la morfología terrestre» (González de Linares, 1878 b, p. 164) se propone para destacar que las formas esferoides son las propias de toda la naturaleza, tanto en el nivel macro como microfísico, lo que es un índice de la forma de lo vivo. He ahí uno de los argumentos que acompañan a la tesis de que los astros son seres vivos.

21 El parágrafo 81 de la Kritik der Urteilskraft propone Kant una interesante discusión sobre las formas de aparición de los seres vivos en la naturaleza, diferenciando entre evolución y epigéne- 
sis, pero decantándose por esta última. En su Opus Postumum viene a considerar a la Naturaleza también como ser vivo, cuando afirma: "[...] Igual que son representables las sustancias orgánicas como vivas, cabría representarse del mismo modo a la tierra entera, pues los animales son alimento mutuo unos de otros, como lo son también los vegetales para los animales, de modo que hay que considerar a todos ellos en conjunto como formando un todo orgánico, no solo mecánico. Son máquinas, pero no la tierra misma» (Kant, 1991b, p. 199 <Ak XXXII,276>).

22 Algunos especialistas coetáneos de González de Linares tenían en alta estima estas incursiones teóricas de nuestro naturalista, más propias de un filósofo de la naturaleza que de un científico. Y lo hacían con respeto, atribuyéndole una autoridad en la materia, como se recoge en una obra que, publicada por primera vez en 1890, por los prestigiosos naturalistas I. Bolívar, S. Calderón y F. Quiroga, los Elementos de Historia Natural, fue constantemente reeditada, alcanzando gran difusión en el mundo académico. La cita que aportamos es de la edición de 1920, cuando Quiroga ya había desaparecido de la nómina. Dice así: «Los caracteres indicados, con ser los más importantes para distinguir los organismos y distinguirlos de los minerales, no tienen, sin embargo, el valor absoluto que parecen revestir a primera vista, porque se fundan esencialmente en negar los conceptos de vida y de individualidad de los segundos; lo cual, si parece muy natural tratándose de las piedras, no lo es tanto cuando se considera a los astros como las individualidades minerales, según el punto de vista del profesor González de Linares. Cada cuerpo celeste recorre, en efecto, un ciclo desde un estado inicial hasta otro final, y en este concepto es un verdadero individuo, siquiera sea de una categoría especial. De lo dicho se infiere que las denominaciones de orgánico o inorgánico, aunque universalmente empleadas, son en realidad inexactas, pues hasta en el concepto filosófico de la palabra, orgánico lo es todo en el mundo, y si se quiere indicar con aquel calificativo como acontecía en la infancia de la ciencia biológica, que los seres así distinguidos poseen órganos, hoy sabemos que no sucede esto en muchos vegetales y animales sencillísimos, reducidos no más que a células aisladas o agrupaciones homogéneas de ellas». Finalmente, en nota comentan que la distinción de G. de Linares se establece entre sidéreos o inorgánicos y episidéreos u orgánicos (Bolívar y Calderón, 1920, p. 4)

23 Es significativo que para resaltar sus tesis de filosofía natural nuestro autor no solo se apoye en sus filósofos de cabecera, como Leibniz, Kant, Schelling, Goethe, Oken y, sobre todo, Carus, sino que invoque también la autoridad de la Escolástica, y de Tomás de Aquino en particular. En este último caso se remite a la Summa Theologicae cuando interpreta la categoría de materia prima como «la base para el espacio infinito y los espacios ilimitados: exigiéndose, por tanto, que se organice paralelamente á la conciencia del sér y séres naturales la forma y for- mas especiales de su materia respectiva» (González de Linares, 1877a, p. 156). También en su trabajo sobre el individuo natural apela en dos ocasiones a la autoridad de la Escolástica del siglo XIII para reforzar la idea de unidad del ser como representación de la naturaleza toda (González de Linares, 1891, p. 78), propugnando la determinación absoluta del mismo, cuando cita el aforismo Ens omnino determinatum (González de Linares, 1891, p. 109).

24 Por cierto, que ese mismo artículo sirve a nuestro naturalista para denunciar las graves dificultades por las que atraviesa la ciencia en España relativas al desconocimiento del estado de la investigación que se hace fuera, por ser muy lento y difícil el acceso a las publicaciones extranjeras (González de Linares, 1891, 339, p. 96).

25 Aún cuando en esta obra, el esfuerzo de Kant no se oriente hacia el estudio del mundo orgánico, la visión que suministra de la Naturaleza no es mecanicista. Las definiciones, los teoremas, las observaciones y los corolarios del capítulo segundo, dedicado a la Dinámica, nos presentan una materia en movimiento impulsada por las fuerzas opuestas de la expansión y la atracción (Kant, 1991a, pp. 43-102).

26 Véase Nieto Blanco (2010). La cuestión del llamado «krauso-positivismo» - término introducido por Alfredo Posada en 1892, denominado también "krausismo positivo», se ha convertido en un tópico historiográfico no exento de debate por la posible oscuridad que el neologismo genera. El origen de esta confusión podría estar en la naturaleza de lo que se entienda por positivismo - término al que se abrazaría el krausismo- si se lo define de manera estática, sin las pertinentes variaciones semánticas que recorre la historia de este concepto en la segunda mitad del siglo XIX. Sin llegar a las hiperbólicas tesis de Flint (1874) y Sanpere y Miquel (1883), o a las más templadas de Tiberghien (1883), que conceden escasa o nula originalidad a Spencer en comparación con Krause, nuestra posición se aleja de quienes, aún reconociendo su legado, otorgan relevancia a este tópico historiográfico (Nuñez, 1987) y se aproxima a los que conceden poco entidad a este asunto (Baratas, 1997; Capellán, 2006; García Cué, 1985; Jerez Mir [en Sales y Ferré, 2001]; Jiménez García, 1986, 1996; Lissorgues, 1998; Otero Carvajal \& López Sánchez, 2012). Por lo que se refiere a Augusto González de Linares, no hemos encontrado en sus escritos ninguna base que nos aconseje encuadrarlo dentro del llamado krauso-positivismo, pues tanto su evolucionismo, como su naturalismo organicista, así como su defensa de una visión especulativa que justifique la naturaleza del conocimiento científico, incluida la alta función que otorga a la ciencia, proceden fundamentalmente, aunque no exclusivamente, de fuentes intelectuales krausistas, complementadas con la práctica de la biología experimental. 


\section{BIBLIOGRAFÍA}

Baratas Díaz, Luis Alfredo (1997), Introducción y desarrollo de la biología experimental en España entre 1868 y 1936, Madrid, CSIC.

Bolívar, Ignacio; Calderón, Salvador (1920), Elementos de Historia Natural, Madrid, Imprenta de March y Samarán, 3a ed. [Primera ed.: Bolívar, Ignacio; Calderón, Salvador; Quiroga, Francisco (1890), Madrid, Establecimiento Tipográfico de Fortanet].

Breidbach, Odenthal von O. (1993), "Evolutionskonzeptionen in der frühen Romantik". En: Gloy, Karen and Burger, Paul (eds.), Die Naturphilosophie im Deutschen Idealismus, Stuttgart, Frommann-Holzboog, pp. 321-336.

Calderón, Salvador (1881), "Evolución geológica”, Boletín de la Real Sociedad Española de Historia Natural, 10, pp. 15-47.

Capellán de Miguel, Gonzalo (2006), La España armónica. El proyecto del krausismo español para una sociedad en conflicto, Madrid, Biblioteca Nueva, Prólogo de M. Suárez Cortina.

Coleman, William (1983), La biología en el siglo XIX. Problemas de forma, función y transformación, México, F.C.E., trad. de G. Guerrero.

Darwin, Charles Robert (2009), El origen de las especies, Edición conmemorativa, Madrid, Espasa Calpe. [Ed. de J. Josa i Llorca que reproduce la traducción que A. Zulueta hizo en 1921 para la Editorial Calpe de Madrid de la sexta edición inglesa].

Flint, Robert (1874), La filosofía de la historia en Alemania, Madrid La España Moderna, s.f., trad. de M. Alonso Paniagua.

García Cué, Juan Ramón (1985), Aproximación al estudio del krausismo andaluz, Madrid, Tecnos.

González de Linares, Augusto (1866), "Goethe considerado como naturalista y como filósofo de la naturaleza", La Enseñanza. Revista general de Instrucción pública, Archivos y Bibliotecas, 29, pp. 65-67.

González de Linares, Augusto (1874), Ensayo de una introducción al estudio de la Historia Natural, Madrid, Imprenta y Estereotipia de M. Rivadeneyra, pp. 5-52.

González de Linares, Augusto (1875), "Sobre las fuentes de conocimiento y el método de enseñanza en los estudios superiores de Historia Natural", Revista de la Universidad de Madrid, 2a época, V, pp. 271-285.

González de Linares, Augusto (1877a), "La Geometría y la Morfología de la Naturaleza", Revista de España, 222, pp. 145-159; 232, pp. 537-550.

González de Linares, Augusto (1877b-1878), “La morfología de Haeckel: antecedentes y crítica", Boletín de la Institución Libre de Enseñanza, 5, pp. 18-19; 9, pp. 34-35; 10, p. 39; 14, pp. 5354; 15, p. 58; 19, p. 74; 20, p. 78; 21, pp. 81-82; 23, p. 12.

González de Linares, Augusto (1877c), "La morfología de Haeckel: antecedentes y crítica", Revista Europea, 176, p. 63; 189, p. 479; 194 , p. $640 ; 199$, pp. $798-799$

González de Linares, Augusto (1878), La célula Vegetal: contradicción que envuelve su concepto en la Botánica contemporánea, Madrid, s.n., pp. 475-485.
González de Linares, Augusto (1878a), "La morfología de Haeckel: antecedentes y crítica”, Revista Europea, 202, p. 32; 203, pp. 62-63.

González de Linares, Augusto (1878b), "Sobre el criterio actual de la morfología terrestre", Boletín de la Institución Libre de Enseñanza, 43, pp. 164-165.

González de Linares, Augusto (1878c), "Sobre la clasificación de las figuras geométricas", Boletín de la Institución Libre de Enseñan$z a, 22$, pp. 1-2.

González de Linares, Augusto (1879a), "La Geografía actual y la figura de la Península Ibérica", Revista de España, 277, pp. 5-22.

González de Linares, Augusto (1879b), “La Geometría y la Morfología de la Naturaleza”, Revista de España, 264, pp. 474-487; 274, pp. 185-196.

González de Linares, Augusto (1884), “Intervención de los animales en la reproducción de las plantas. Dos precursores de Darwin", Revista de España, 403, pp. 358-370.

González de Linares, Augusto (1885), "Sobre la fecundación vegetal", Boletín de la Institución Libre de Enseñanza, 202, pp. 199-202.

González de Linares, Augusto (1890), “Preocupaciones abstractas sobre la noción de espacio", Boletín de la Institución Libre de Enseñanza, 316, pp. 106-109.

González de Linares, Augusto (1891), “Conceptos actuales sobre el individuo natural", Boletín de la Institución Libre de Enseñanza, 338, pp. 78-80; 339, pp. 95-96; 340, pp. 108-110.

González de Linares, Augusto (1892a), “El parentesco genealógico y el supuesto ideal en la naturaleza", Boletín de la Institución Libre de Enseñanza, 375, pp. 283-284.

González de Linares, Augusto (1892b), "La individualidad vegetal", Boletín de la Institución Libre de Enseñanza, 358, pp. 11-13.

González de Linares, Augusto (2004), La vida de los astros, Santander, Servicio de Publicaciones de la Universidad de Cantabria, ed. y Estudio preliminar de Carlos Nieto Blanco.

González de Linares, Augusto (en prensa), Obra completa, Santander, Real Sociedad Menéndez Pelayo, ed. y Estudio preliminar de Carlos Nieto Blanco.

Haeckel, Ernst (1887), Morfología general de los organismos, BarceIona, Blas Barrera y Compañía, trad. y prol. de Sanpere y Miquel, revisada por el Dr. G. Sentiñón.

Helmholtz, Hermann Ludwig Ferdinand von (1876), "Relaciones de la ciencia de la Naturaleza con la ciencia toda", Revista Europea, 128, pp. 177-181; 129, pp. 193-200, trad. de A. González de Linares.

Jahn, Ilse (1994), "On the Origin of Romantic Biology and Its Further Development at the University of Jena Between 1790 and 1850". En: Poggi, Stefano y Bossi, Maurizio (eds.), Romanticism in Science, Dordrecht-Boston-London, Kluwer Academic Publishers, pp. 75-90 
Jiménez García, Antonio (1986), "La implantación del Krausopositivismo en España". En: Actas del IV Seminario de Historia de la Filosofía Española, Salamanca, Universidad, pp. 649-659.

Jiménez García, Antonio (1996), El krausopositivismo de Urbano González Serrano, Badajoz, Departamento de Publicaciones de la Excma. Diputación Provincial.

Jiménez-Landi, Alfredo (1987), La Institución Libre de Enseñanza. 2. Periodo Parauniversitario, 2 vols., Madrid, Taurus.

Jobit, Pierre (1936), Les éducateurs de l'Espagne contemporaine, I, Les krausistes, París, E. De Boccard.

Kant, Immanuel (1991a), Principios metafísicos de la ciencia de la naturaleza, Madrid, Tecnos, ed. y trad. de J. Aleu Benítez.

Kant, Immanuel (1991b), Transición de los principios metafísicos de la ciencia natural a la física (Opus Postumum), Barcelona, Anthropos, ed. y trad. de F. Duque.

Kant, Immanuel (2001), Crítica del discernimiento, Madrid, Antonio Machado Libros, 2001, ed. de R. R. Aramayo y S. Mas.

Lissorgues, Yvan (1998), "Krauso-positivismo, vulgar denominación para un gran pensamiento (o el espíritu sobre todas las cosas)". En: Lissorgues, Yvan and Sobejano, Gonzalo (coords.), Pensamiento y literatura en España en el siglo XIX. Idealismo, Positivismo, Espiritualismo, Toulouse, P. U. du Mirail, pp. 321-333.

Montiel, Luis (1997), "Texto ejemplar. Una Summa de la Filosofía de la naturaleza del Romanticismo alemán: el Lehrbuch der $\mathrm{Na}$ turphilosophie de Lorenz Oken (I)", Asclepio, XLIX (2), pp. 85-99.

Montiel, Luis (1999), "Una Summa de la Filosofía de la naturaleza del Romanticismo alemán: el Lehrbuch der Naturphilosophie de Lorenz Oken (II)", Asclepio, LI (2), pp. 205-220.

Müller, Gerhard H. (1994), "Wechse/wirkung in the Life and Other Sciencies: A Word, New Claims and a Concept Around 1800... and Much Later". In: Poggi, Stefano and Bossi, Maurizio (eds.), Romanticism in Science, Dordrecht-Boston-London, Kluwer Academic Publishers, pp. 1-14.

Nieto Blanco, Carlos (2009), El naturalista Augusto González de Linares (1845-1904). Ensayo de una biografía intelectual, Madrid, Fundación Ignacio Larramendi [en línea], disponible en: www. larramendi.es, [consultado el 27/08/2013].

Nieto Blanco, Carlos (2010), "Un krausista en el laboratorio. La aportación del naturalista Augusto González de Linares (18451904)", Revista de Hispanismo Filosófico, 15, pp. 77-101.
Nieto Blanco, Carlos (2011), "Ciencia y Krausismo. González de Linares y Menéndez Pelayo". En: Mandado Gutiérrez, Ramón Emilio y Bolado Ochoa, Gerardo (dirs.), "La Ciencia Española". Estudios, Santander, PubliCan-Ediciones de la Universidad de Cantabria-RSMP, pp. 81-107.

Núñez, Diego (1987), La mentalidad positiva en España, Madrid, Ediciones de la Universidad Autónoma de Madrid, 2ae ed.

Otero Carvajal, Luis Enrique y López Sánchez, José María (2012), La lucha por la modernidad. Las ciencias naturales y la Junta para Ampliación de Estudios, Madrid, CSIC-Residencia de Estudiantes.

Pérez, Antonio (2003), "Filosofía de la naturaleza y ciencia: Schelling". En: Montesinos, José, Ordóñez, Javier y Toledo, Sergio (eds.), Ciencia y romanticismo, La Orotava, Fundación Canaria Orotava de Historia de la Ciencia, pp. 43-70.

Posada, Alfredo (1892), "Los fundamentos psicológicos de la educación según el Sr. González Serrano", Boletín de la Institución Libre de Enseñanza, 358, pp. 1-9; 359, pp. 17-20.

Schelling, Friedrich Wilhelm Joseph (1996), Escritos sobre filosofía de la naturaleza, Madrid, Alianza, ed. de A. Leyte.

Sales y Ferré, Manuel (2005), Sociología general, Madrid, Centro de Investigaciones Sociológicas y Boletín Oficial del Estado, ed. y Estudio introductorio de R. Jerez Mir.

Sanpere y Miquel, Salvador (1883), "Prólogo". En: Spencer, Heriberto, El Universo social (Sociología general y descriptiva), I, Barcelona, Barris y Cía, pp. 5-48, trad. de S. Sanpere y Miquel.

Serrano y Fatigati, Enrique y Calderón, Salvador (1870), Estudios de Filosofía natural. Total organización de la materia, Madrid, Imprenta de M. Tello.

Simó Ruescas, Julio (2004), "La Naturphilosphie en España. La recepción del evolucionismo en el entorno de la tradición krausista", Asclepio, LVI (2), pp. 197-222.

Simó Ruescas, Julio (2011), "Evolución, progreso, devenir: la filosofía de la naturaleza del institucionismo". En: Suárez Cortina, Manuel, Libertad, armonía, tolerancia. La cultura institucionista en la España contemporánea, Madrid, Tecnos, pp. 119-141.

Tiberghien, Guillaume (1883), Krause y Spencer, Madrid, Fernando Fe, trad., precedida de una biografía del autor, de H. Giner de los Ríos.

Tollinchi, Esteban (1989), Romanticismo y modernidad. Ideas fundamentales de la cultura del Siglo XIX, I, Universidad de Puerto Rico. 